\title{
Cytidine deaminase activity in synovial fluid of patients with rheumatoid arthritis: relation to lactoferrin, acidosis, and cartilage proteoglycan release
}

\author{
B Månsson, P Geborek, T Saxne, S Björnsson
}

\begin{abstract}
It is claimed that cytidine deaminase activity reflects local granulocyte turnover or activity in the synovial fluid of patients with rheumatoid arthritis, but cytidine deaminase is not a granulocyte specific enzyme. Lactoferrin is a granulocyte specific protein that is released from the secondary granulae during activation. We measured cytidine deaminase activity and lactoferrin concentrations in 33 rheumatic synovial fluid samples. Cytidine deaminase activity and lactoferrin concentrations correlated closely, indicating that both analyses reflect similar events in the joint-that is, result in their release from granulocytes. Cytidine deaminase activity and granulocyte concentrations correlated less closely, suggesting that there are additional factors besides the cell number which contribute to this release. Joint acidosis may be one such factor, as pH and cytidine deaminase activity correlated inversely. There was no association with synovial fluid proteoglycan concentrations, a marker of cartilage degradation.
\end{abstract}

Several non-specific serum analyses, such as erythrocyte sedimentation rate (ESR), C reactive protein (CRP), haptoglobin, orosomucoid, and platelet count have been used to assess inflammatory activity in rheumatic diseases. ${ }^{1}$ In measurements of synovial fluid the white cell count is commonly used. Measurements of markers reflecting the activity of inflammatory cells known to be present in arthritic joints should provide more specific information on the activity of rheumatoid inflammation, ${ }^{2-11}$ which might facilitate the understanding of basic disease processes and also provide information on the effects of drugs on these processes.

Granulocyte specific enzymes or molecules are released from both the primary (azurophilic) granulae, such as myeloperoxidase and elastase, and the secondary (specific) granulae, such as lactoferrin and collagenase. ${ }^{12}$ Myeloperoxidase in the serum and synovial fluid, ${ }^{10}$ as well as circulating elastases has recently been reported in patients with rheumatoid arthritis. ${ }^{5}$ Other less granulocyte specific enzymes have also been used to assess the inflammatory activity of these cells, such as lysozyme ${ }^{7}$ and cytidine deaminase. $^{2-4}$ The cytoplasmatic enzyme cytidine deaminase is thought to be released from granulocytes during phagocytosis and cell lysis, or both ${ }^{2}$ and its release might thus reflect granulocyte turnover or activity, rather than just their numbers. The activity of cytidine deaminase is measured as the amount of ammonia formed from deamination of cytidine. ${ }^{12}$ Although not granulocyte specific, it has been used to monitor local and systemic inflammatory disease activity. ${ }^{2-4} \mathrm{~A}$ close relation between synovial fluid granulocyte concentration and cytidine deaminase activity has been reported, whereas the correlation between blood cytidine deaminase activity and ESR and CRP was much lower. ${ }^{2}$ It has been claimed that blood cytidine deaminase activity better reflects inflammatory activity than ESR or CRP values in rheumatoid arthritis. ${ }^{313}$

Cytidine deaminase is present in several types of cells, such as liver, lung, kidney, and also in minute amounts in lymphocytes. ${ }^{2}$ Cytidine deaminase activity should therefore be tested against more specific markers of granulocyte activity. Lactoferrin is an iron binding protein which is released from the specific granulae during activation; it has been used to assess the activity of the granulocytes in rheumatoid arthritis. ${ }^{7}$ We therefore measured cytidine deaminase activity and lactoferrin concentrations in synovial fluid samples from patients with rheumatoid arthritis. We also measured $\mathrm{pH}$, $\mathrm{PCO}_{2}$ and cartilage proteoglycan concentrations in the fluids to study the relation between cytidine deaminase activity, and tissue metabolism and cartilage degradation.

\section{Methods}

Thirty three knee joints with effusive synovitis in 24 patients (16 women, eight men) with rheumatoid arthritis were studied. ${ }^{14}$ Median age was 61 years (range 24-74), duration of disease six years, (range one to 30 ), and duration of local synovitis four weeks (one to 52). Eighteen patients were treated with non-steroidal antiinflammatory drugs (NSAIDs), nine with second line drugs (chloroquine, sulphasalazine, podophyllotoxin), and six with prednisolone ( $<8 \mathrm{mg}$ daily). In nine patients both knee joints were studied. All joint aspirations were performed for therapeutic reasons. Synovial fluid was sampled using a conventional aseptic technique through a $1.2 \mathrm{~mm}$ bore needle. No local anaesthetic was used. All accessible synovial fluid was withdrawn and the volume recorded. The samples were drawn at about noon and after at least 10 minutes of bed rest. Synovial fluid was collected in $(a)$ sterile tubes containing EDTA, immediately chilled to $0^{\circ} \mathrm{C}$, centrifuged, and the supernatant stored at $-80^{\circ} \mathrm{C}$; (b) sterile glass syringes, which were immediately sealed and put on ice for analyses of $\mathrm{pH}$ and $\mathrm{PCO}_{2} ;(c)$ EDTA tubes for cell counting. 
Cytidine deaminase activity was measured on frozen samples which had not undergone previous hyaluronidase treatment or deproteinisation, essentially according to the method described by Jones and Roberts. ${ }^{15}$ All samples were analysed in one series in quadruplicate with an individual blank. Synovial fluid samples were diluted $1 / 8$ in blank buffer. A $50 \mu \mathrm{l}$ aliquot was incubated for 16 hours at $37^{\circ} \mathrm{C}$ with either $75 \mu$ l cytidine buffer or blank buffer. The buffers comprised $0 \cdot 1 \mathrm{M}$ sodium carbonate/ bicarbonate (pH 9.2) with or without $4 \cdot 1$ $\mathrm{mmol} / \mathrm{l}$ cytidine (Sigma). The amount of ammonia formed was determined as follows: $750 \mu \mathrm{l}$ phenol solution (10 g/l phenol, $50 \mathrm{mg} / 1$ sodium nitroprusside) and $750 \mu l$ hypochlorite solution ( $5 \mathrm{~g} / 1$ sodium hydroxide, $21 \cdot 3 \mathrm{~g} / 1$ disodium hypochlorite) were added and incubated for two hours at $37^{\circ} \mathrm{C}$ to allow the reaction to be completed. The end point absorbance was measured using a Titertek ELISA multiscan at dual wavelengths of $620 \mathrm{~nm}$ and $450 \mathrm{~nm}$. A standard curve of $\mathrm{NH}_{4} \mathrm{Cl}$ diluted in blank buffer was prepared and the enzyme activity was expressed as the amount of ammonia liberated from the samples. Only analyses with at least three of the quadruplicates within $10 \%$ of the mean were accepted. About $50 \%$ increased sensitivity was obtained compared with the original method.

Lactoferrin was measured using a specific electroimmunoassay after the samples had been treated with bovine testes hyaluronidase (Hyalase, Leo, Helsingborg, Sweden). ${ }^{16}$ The lower detection limit was $0.008 \mathrm{~g} / \mathrm{l}$. Measurements of $\mathrm{pH}$ and $\mathrm{PCO}_{2}$ were performed with an ABL300 radiometer (Radiometer, Copenhagen, Denmark) within 15 minutes of sampling. Proteoglycan was measured using an enzyme linked immunosorbent assay (ELISA) with polyclonal antibodies specifically recognising the core protein of the large, aggregating cartilage proteoglycan, as described previously. ${ }^{17}$ Synovial fluid leucocytes were counted after dilution with saline, and a differential count was made after staining with May-Grünwald-Giemsa.

Spearman's rank correlation coefficient was used for statistical analysis. Owing to the multiple correlations performed a $p$ value of $<0.01$ was regarded as significant.

\section{Results}

Cytidine deaminase activity in synovial fluid correlated most closely with lactoferrin concentrations, but the correlation with granulocyte

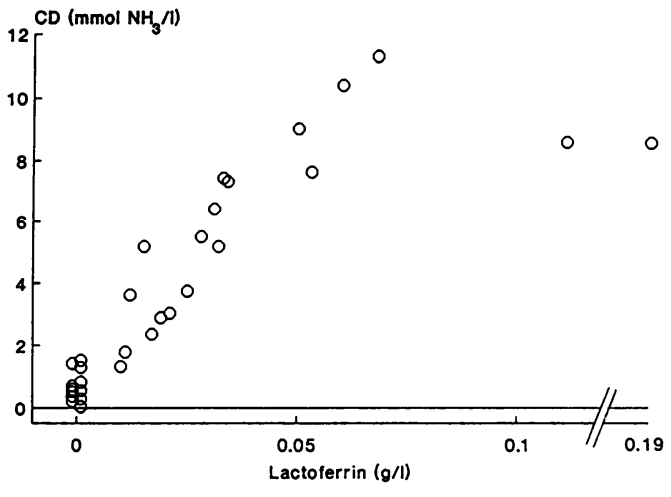

Figure 1: Lactoferrin concentrations compared with cytidine deaminase $(C D)$ activity in the synovial fluid. Note that the abscissa has been broken.

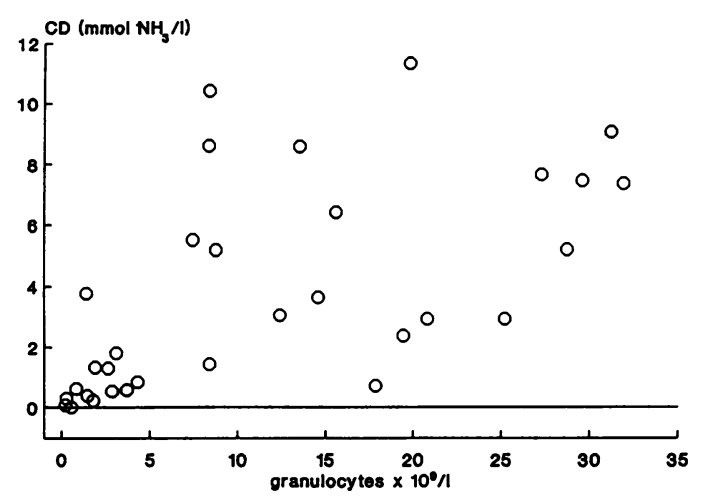

Figure 2: Synovial fluid granulocyte concentrations compared with cytidine deaminase $(C D)$ activity.

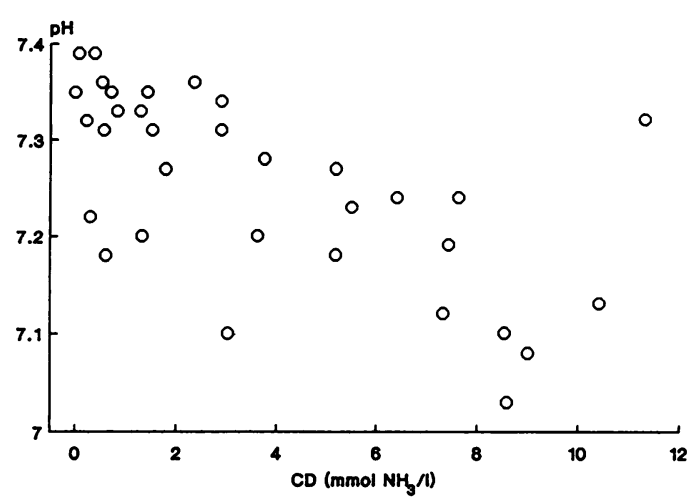

Figure 3: Synovial fluid cytidine deaminase (CD) activity compared with $p H$.

Spearman's correlation coefficients for synovial fluid concentrations of granulocytes, mononuclear cells, lactoferrin, proteoglycan, cytidine deaminase activity, pH, and $\mathrm{PCO}_{2}$

\begin{tabular}{|c|c|c|c|c|c|c|c|c|}
\hline & $\begin{array}{l}\text { Mononuclear } \\
\text { cells }\end{array}$ & $p H$ & $\mathrm{PCO}_{2}$ & $\begin{array}{l}\text { Cytidine } \\
\text { deaminase }\end{array}$ & Lactoferrin & Proteoglycan & Median & $\begin{array}{l}\text { Minimum- } \\
\text { maximum }\end{array}$ \\
\hline \multirow{2}{*}{$\begin{array}{l}\text { Granulocytes }\left(\times 10^{9} /\right) \\
\text { Mononuclear cells }\left(\times 10^{9} / \mathrm{l}\right) \\
\text { pH } \\
\text { Pco }(k P a) \\
\text { Cytidine deaminase } \\
\left.\text { (mmol NH })_{3}\right) \\
\text { Lactoferrin }(\mathrm{g} / \mathrm{l}) \\
\text { Proteoglycan }(\mathrm{mg} / \mathrm{l})\end{array}$} & 0.42 & $\begin{array}{l}0.37 \\
0 \cdot 12\end{array}$ & $\begin{array}{c}0.47^{*} \\
0.12 \\
-0.90^{* *}\end{array}$ & $\begin{array}{l}0.67^{* *} \\
0.03 \\
-0.65^{* *} \\
0.65^{* *}\end{array}$ & $\begin{array}{l}0.67^{* *} \\
0.08 \\
-0.60^{* *} \\
0.72^{* *}\end{array}$ & $\begin{array}{r}0.05 \\
0.21 \\
0.06 \\
-0.03\end{array}$ & $\begin{array}{l}8 \cdot 4 \\
3 \cdot 0 \\
7 \cdot 27 \\
7 \cdot 5\end{array}$ & $\begin{array}{l}(0 \cdot 3-31 \cdot 9) \\
(0 \cdot 6-11 \cdot 2) \\
(7 \cdot 03-7 \cdot 39) \\
(5 \cdot 7-10 \cdot 5)\end{array}$ \\
\hline & & & & & $0.94^{* *}$ & $\begin{array}{r}-0.06 \\
0.00\end{array}$ & $\begin{array}{l}1 \cdot 8 \\
0 \cdot 0145 \\
66\end{array}$ & $\begin{array}{l}(0 \cdot 1-7 \cdot 5) \\
(0 \cdot 008-0 \cdot 19) \\
(10-602)\end{array}$ \\
\hline
\end{tabular}




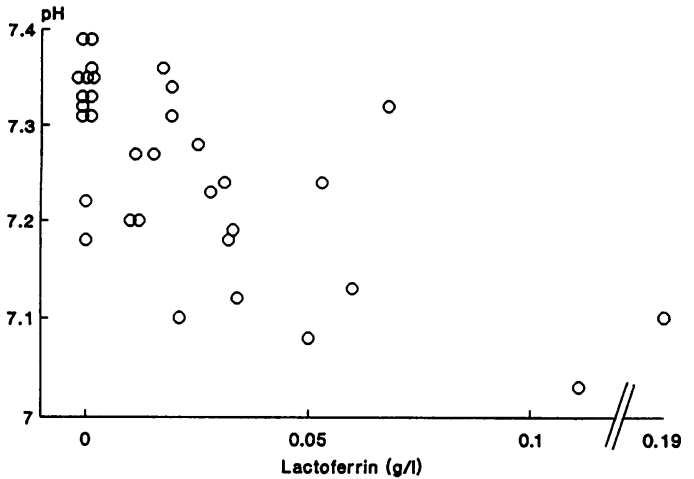

Figure 4: Synovial fluid lactoferrin concentrations compared with $\mathrm{pH}$. Note that the abscissa has been broken.

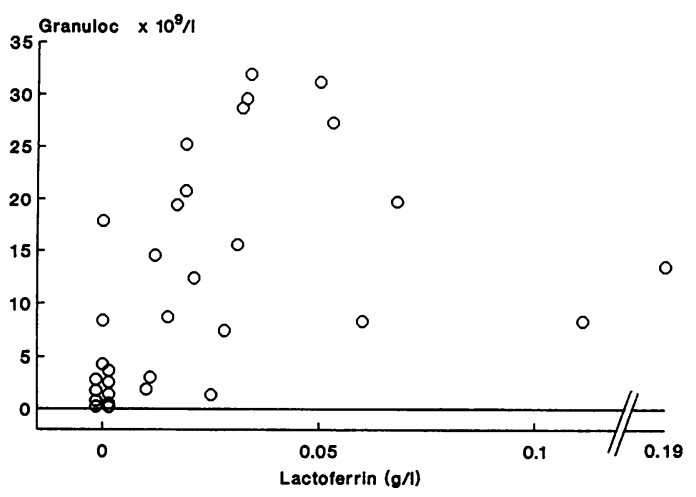

Figure 5: Synovial fluid lactoferrin concentrations compared with granulocyte concentrations. Note that the abscissa has been broken.

concentrations, $\mathrm{pH}$, and $\mathrm{PCO}_{2}$ was also highly significant (table, figs 1-3). The negative correlation between lactoferrin and $\mathrm{pH}$ was highly significant, and the two highest lactoferrin concentrations also had a low pH (fig 4). Figure 5 illustrates the significant correlation between lactoferrin and granulocytes. In contrast, the mononuclear cell concentrations did not correlate with the other variables. The proteoglycan concentrations did not correlate with metabolic or cellular variables (table).

There was no significant correlation between age, duration of synovitis, duration of disease, synovial fluid volume, or any of the other variables.

\section{Discussion}

Cytidine deaminase activity in blood is lower than the corresponding synovial fluid activity in rheumatoid arthritis, indicating that cytidine deaminase is released locally in the joint. ${ }^{2}$ The cells that contain most cytidine deaminase activity in the inflamed joint are granulocytes. ${ }^{2}$ Cytidine deaminase activity in synovial fluid and blood samples has been reported not to be influenced by four hours of incubation at room temperature before cell separation. ${ }^{2}$ Shaking samples, however, may activate granulocytes. ${ }^{19}$ The actual processing, with immediate chilling of the samples and rapid cell separation, should minimise possible in vitro artefacts. As cytidine deaminase is not specific for granulocytes ${ }^{2}$ it was important to ascertain if the enzyme was released from these cells. Lactoferrin is specific for granulocytes and is released during phago- cytic activity from the specific granules. ${ }^{12}$ The close correlation between lactoferrin concentrations and cytidine deaminase activity indicates that both assays measure similar events in the joint of patients with rheumatoid arthritis. We suggest that granulocyte lysis is the mechanism of this cellular release. Lactoferrin release may occur both by degranulation and by cell lysis. Both events reflect the overall cell activity of granulocytes in the rheumatic joint. Lysozyme, another enzyme present in granulocytes as well as in macrophages correlated less well with lactoferrin concentrations in synovial fluid of patients with rheumatoid arthritis. Caution is therefore needed when suggesting mechanisms of cellular release and the cellular origin of molecules in the synovial fluid.

Although the correlation between cytidine deaminase activity and granulocyte concentration in this study $\left(r_{s}=0.67\right)$ was significant, it was still less than the close correlation described earlier $(r=0.93){ }^{2}$ Local metabolism may contribute to the release of cytidine deaminase and lactoferrin, as suggested by the correlation with joint acidosis. Our results suggest that not only the amount of granulocytes present in synovial fluid but also their turnover and actual degree of activation is reflected in synovial cytidine deaminase and lactoferrin concentrations. The two joints with the highest lactoferrin concentrations showed acidosis, but were not particular in any other respect.

Proteoglycans are released into synovial fluid from cartilage in both inflammatory and degenerative joint diseases. ${ }^{1718}$ The synovial fluid content most probably reflects continuing cartilage degradation. ${ }^{17} 18$ The lack of correlation between proteoglycan concentrations and the other variables indicates that the release of proteoglycans is not directly mediated by granulocyte activity or joint acidosis. Several other mechanisms, such as cytokine activation, probably contribute to proteoglycan degradation. ${ }^{20}$

In conclusion, cytidine deaminase activity in synovial fluid seems to be a marker of local granulocyte turnover or activity, or both, which should prove useful for monitoring the local inflammatory response in rheumatoid arthritis and possibly in other joint diseases. Although less specific, it should provide similar information on inflammatory synovial fluid granulocyte turnover as the more complicated and insensitive lactoferrin assay.

This investigation was supported by grants from Alfred Österlunds stiftelse, Greta och Johan Kocks stiftelser, Crafoordska stiftelsen, and the University of Lund. We thank Professor Anders Grubb, department of clinical chemistry, Lund, for help with the lactoferrin analyses. We also thank Gertrud Hellmer Ursula Endresen, and Lisbeth Granberg for skilful technical assistance.

1 Brahn E, Scoville C D. Biochemical markers of disease activity. Clin Rheumatol 1988; 2: 153-83.

2 Thompson $P$ W, Jones D D, Currey H L F. Cytidine deaminase activity as a measure of acute inflammation in rheumatoid arthritis. Ann Rheum Dis 1986; 45: 9-14.

3 Thompson P W, Jones D D, Currey H L F. Serum cytidine deaminase as an integrated measure of acute inflammation. Br F Rheumatol 1986; 25: 97-8.

4 Thompson P W, Kirwan J R, Jones D D, Currey H L F. Serum cytidine deaminase levels after withdrawal of nonsteroidal anti-inflammatory treatment in rheumatoid arthritis. Ann Rheum Dis 1988; 47: 308-12.

5 Adeyemi E O, Hull R G, Chadwick V S, Hughes G R V, 
Hodgson H J F. Circulating human leucocyte elastase in rheumatoid arthritis. Rheumatol Int 1986; 6: 57-60.

6 Pruzanski W, Saito S, Ogryzlo M A. The significance of lysozyme (muramidase) in rheumatoid arthritis: I. Level in
serum and synovial fluid. Arthritis Rheum 1970; 13: 389-99.

7 Malmquist J, Thorell J I, Wollheim F A. Lactoferrin and lysozyme in arthritic exudates. Acta Med Scand 1977; 202: 313-8.

8 Farr M, Kendall M J, Shuttleworth R, Meynell M J, Hawkins C F. Source and significance of 5-nucleotidase in synovial fluid. Ann Rheum Dis 1973; 32: 326-30.

9 Hälgren R, Bjelle A, Venge P. Eosinophil cationic protein in inflammatory synovial effusions as evidence of eosinophil involvement. Ann Rheum $D$ is 1984 ; 43: 556-62.

10 Edwards S W, Hughes V, Barlow J, Bucknall R. Immunological detection of myeloperoxidase in synovial fluid from patients with rheumatoid arthritis. Biochem $\mathcal{Y} 1988 ; 250$ : patien.

11 Yuksel H, Akoglu T F. Serum and synovial fluid adenosine deaminase activity in patients with rheumatoid arthritis, osteoarthritis, and reactive arthritis. Ann Rheum Dis 1988 47: 492-5

12 Henson P M, Henson J E, Fittschen C, Kimani G, Bratton D L, Riches D W H. Phagocytic cells: degranulation and secretion. In: Gallin J I, Goldstein I M, Snyderman R, eds. Inflammation: basic principles and clinical correlates. New York: Raven Press, 1988: 363-90.
13 Thompson P W. Laboratory markers of joint inflammation and damage. $\mathrm{Br} \mathcal{F}$ Rheumatol 1987; 26: 83-5.

14 Arnett F C, Edworthy S M, Bloch D A, et al. The American Rheumatism Association 1987 revised criteria for the classification of rheumatoid arthritis. Arthritis Rheiom 1988; 31: 315-24.

15 Jones D D, Bahijri S, Roberts E L, Williams G F. Activity of serum cytidine deaminase during pregnancy. $\mathrm{Br} \mathcal{J}$ Obstet Gynaecol 1982; 89: 314-17.

16 Hansen N E, Malmquist J, Thorell J. Plasma myeloperoxidase and lactoferrin measured by radioimmunoassay: relation to neutrophil kinetics. Acta Med Scand 1975; 198: 437.

17 Saxne T, Heinegard D, Wollheim F A. Therapeutic effects on cartilage metabolism in arthritis as measured by release of proteoglycan structures into the synovial fluid. $A n n$ Rheum Dis 1986; 45: 491-7.

18 Saxne $T$, Heinegird D Woilheim F A. Cartilage proteoglycans in synovial fluid and blood in inflammatory joint glycans in synovial fluid and blood in inflammatory joint 1987; 30: 972-9.

19 Jones D D, Roberts E L, Williams G F. Serum cytidine deaminase assay-some pitfalls. Br $\mathcal{F}$ Obstet Gymaecol 1986; 93: 407-10.

20 Dingle J T, Tyler J A. Role of intercellular messengers in the control of cartilage matrix dynamics. In: Knettner $\mathrm{K} \mathrm{E}$ Schlegerbach R, Hascall V C, eds. Articular cartilage biochemistry. New York: Raven Press, 1986: 181-91. 